ANNALS OF “DUNAREA DE JOS” UNIVERSITY OF GALATI
MATHEMATICS, PHYSICS, THEORETICAL MECHANICS
FASCICLE II, YEAR XII (XLIII) 2020, No. 1
DOI: https://doi.org/10.35219/ann-ugal-math-phys-mec.2020.1.07

\title{
Methods of flood risk analysis. Case study Baltenii de Sus locality from the Danube Delta
}

\author{
Alexandru Banescu ${ }^{1,2,}$, Lucian Puiu Georgescu ${ }^{1}$, Catalina Iticescu ${ }^{1}$, \\ Eugen Rusu ${ }^{1}$ \\ 1 "Dunarea de Jos" University of Galati, Faculty of Sciences and Environment, INPOLDE research center, \\ 800008 Galati, Romania \\ 2 "Danube Delta National Institute for Research and Development of Tulcea, Babadag Street,165, RO-820112, \\ Tulcea, Romania \\ *Corresponding author: alexandru.banescu@yahoo.com
}

\begin{abstract}
The objective of this paper is the flood risk analysis for the locality of Baltenii de Sus in the Danube Delta using two methods of analysis. This analysis is based on flow and level measurements both on the Danube and near the analyzed locality. The first method consists of modeling a real scenario of a rupture in the protection dam that surrounds the locality, for a period of 1 day using several flooding stages. The second method consists of GIS analysis, namely the application of the maximum water level over the digital terrain model. The digital terrain model is the information base for this study and is used as the main object in order to apply the 2 methods. The results are in the form of flood hazard maps and digital maps with flooded surfaces of Baltenii de Sus locality. Floods caused by the Danube's peak levels or dam failure can be analyzed through a combination of 1D2D and GIS analysis techniques.
\end{abstract}

Keywords: flood, water level, Danube Delta, scenarios.

\section{INTRODUCTION}

A flood is the covering of a portion of land with a large amount of water (from the overflow of watercourses, rain); large amounts of water from rivers or streams that spill over the banks, due to increased water flow, as a result of sudden melting of snow or heavy rains. The damages caused by floods varies depending on the vulnerability of the affected receiver. Under these conditions, Romania remains one of the countries most vulnerable to these phenomena, primarily due to the lack of a sustainable infrastructure for protection against hazards and due to the irrational exploitation of the territory, such as the irrational exploitation of wood [1].

The knowledge of these phenomena, named in the literature and hazards, allows taking the most appropriate measures, both to mitigate their effects and to reconstruct the affected areas or regions. Mitigation of flood effects can be achieved through structural measures, which involve civil works, construction of dams, reservoirs, canal changes, catchment or drainage or non-structural measures consisting of flood forecasting, flood warning, emergency planning, etc. The effects of floods have shown that traditional flood protection solutions can fail and cause more and more damage $[2,3]$.

Flood risk is characterized by its nature and probability of occurrence. The degree of exposure of the receptors (number of population and assets), the susceptibility to floods of the receptors and their value, resulting implicitly to reduce the risk action, must be taken in relation to these characteristics. Consequently, the acceptable risk must be the result of a balance between the risk and 
the benefits attributed to an activity as a result of flood risk reduction or government regulation. The reduction of damage and of loss of life as a result of floods does not depend only on the response actions taken during floods, actions addressed sometimes separately under the name of emergency management [4].

The diminution of floods consequences is the result of a broad combination between the measures and actions preceding the occurrence of the phenomenon, those of management during the floods, and those undertaken after the floods (reconstruction and lessons learned as a result of the phenomenon) [5].

Based on this analysis and beyond, flood risk can be assessed and compared with the acceptable flood risk established by the affected community on the basis of a set of criteria and standards. This can lay the groundwork for decisions on future action needed, as well as for assessing possible measures to mitigate flood effects. Risk management is a complex process that consists of going through and corroborating several stages in close interaction and which aim at a continuous improvement of the process. It is a process in which both the authorities and researchers have shown a special interest in recent years and the desire to find reliable solutions to reduce the negative effects [6].

The studies and research conducted and presented in this paper started from the idea of developing a feasible methodology for analyzing flood scenarios, in the context of frequent floods in the Danube Delta. The objective of this study is the analysis of flood scenarios for the locality of Baltenii de Sus in the Danube Delta, aiming to obtain the flooding maps using 2 methods of analysis (a dynamic method and a static method).

\section{MATERIALS AND METHODS 2.1. THE STUDY AREA}

The study area is located in the Danube Delta on one the main distributary channels Sfantu Gheorghe. In more detail, in this study the locality of Baltenii de Sus is taken into account, this being located on the Sfantu Gheorghe distributary between the locality Nufaru (west) and the locality Mahmudia (east) (Fig. 1). The analyzed locality is prone to flood risk and is vulnerable to flash floods on the Danube.

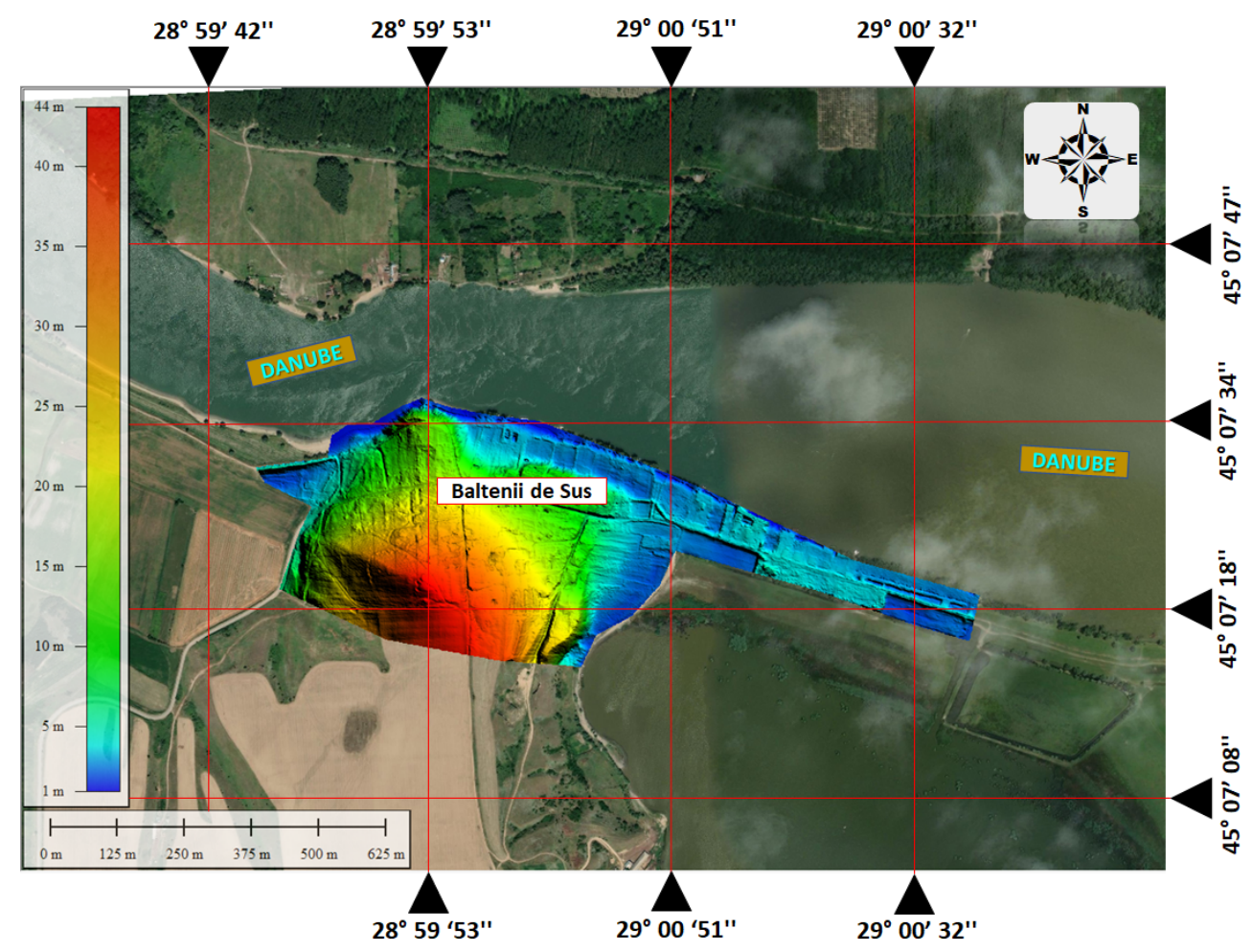


Fig. 1. The location of the target area

As a morphohydrographic unit, the Danube Delta was formed due to the existence of specific conditions: the marine continental shelf with depth and small inclination, to the east; the limanic bay between the Dobrogea platform and the Bugeac platform; the appreciable volume of alluvium brought by the Danube (about 58 million tons/year); circular sea currents at the seashore; very small tidal amplitude in the northwestern part of the Black Sea $(7-11 \mathrm{~cm})$. To these basic conditions were added others, of climatic type (Black Sea level oscillations - eustatic movement) and tectonic (epeirogenic movements in the surrounding areas), which complicated and customized the contouring and evolution of the delta [7].

As for the depressions in the Danube Delta, they are a characteristic element. Their existence is due to the intercalation of water surfaces with compact surfaces and land strips that make up the largest part of the surface of the Danube watershed. Deltaic depressions are actually the islands of the delta. Their interior is located below the height of the marginal ridges and has a low area, so it becomes floodable as the level of the Danube rises on the main distributaries. Large islands are complex formations, built of many elements of the hydrographic network and smaller islands that, due to the different degree of clogging, are located at various altitudes. The analyzed locality is located in the fluvial Delta [8].

The fluvial delta is located west of the Letea, Caraorman, and Crasnicol maritime ridges. Its fluvial character is imprinted by the composition of the surface lithology, in which the marine elements are totally missing. They are also characterized by a wide spread of deltaic depressions and the presence of remnants of the predeltaic land. The meadow sectors on the right of the Sfantu Gheorghe distributary are in an advanced stage of clogging. Most of their surfaces are covered with alluvial soils in varying degrees of changes, and vegetation is cultivated [9].

Regarding the variations of the levels during the year at Ceatal Chilia, determines the corresponding variations of the levels on the main distributary. Therefore, the formation of a clear image regarding the particularities of the variation of the levels during the year, as well as the calculation of the different characteristic sizes of the regime, are not possible without a genetic analysis of the water flow at Ceatal Chilia. The distribution of water runoff at Ceatal Chilia depends largely on the character of the tributary rivers of the Danube, which is in turn determined by the climatic factors of the runoff in the physical-geographical conditions specific to the tributary basins. Therefore, the explanation of the level regime during the year will be closely related to the action of these factors on the complex processes of runoff formation throughout the Danube basin [10].

In the downstream areas of the delta, the maximum levels appear especially in May, but also in June and July, as a result of floods that intensify the levels and flows on the river. In 2010, largescale floods were recorded in the Danube Delta due to high levels on the Danube. This phenomenon was strongly felt in the localities distributed on the main distributaries of the Danube. The localities on the main distributary of Sfantu Gheorghe were also affected due to this phenomenon which caused significant damage to households and infrastructure.

\subsection{FLOOD RISK ANALYSIS FOR THE STUDY AREA - BALTENII DE SUS LOCALITY ON THE SFANTU GHEORGHE BRANCH}

In the flood risk analysis for Baltenii de Sus locality, a methodology is proposed that uses 2 methods (Fig. 2). The first (dynamic) method was applied to Baltenii de Sus locality by modeling a real scenario of breaking the protection dam, the rupture being caused by the high levels on the Sfantu Gheorghe distributary. The rupture in the protection dam has a width of 30 meters opening and is maintained for a period of 24 hours at maximum levels of the Danube.

The second (static) method was applied to Baltenii de Sus locality by modeling an identical scenario as in the first method, the difference consisting in the period of maintaining the rupture in the protection dam, this being much longer. The approach of the 2 methods is done using 2 different software. The HEC-RAS hydraulic modeling program is used for the dynamic method, and the Global Mapper GIS analysis program is used for the static method. 


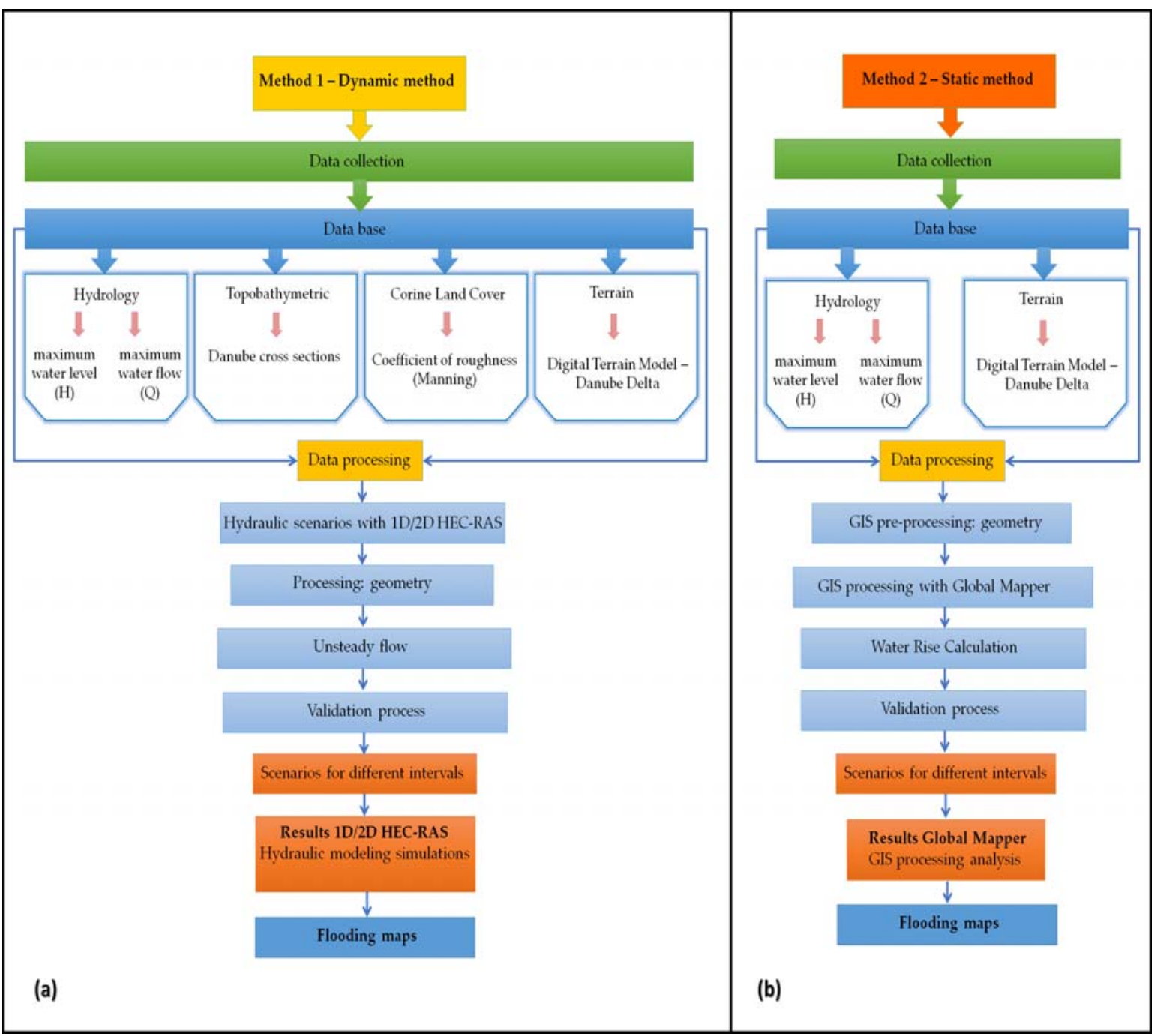

Fig. 2. The methodology considered in the present work. (a) description of the steps of method 1 dynamic; (b) description of the steps of method 2 - static.

Data collection is the most important step in flood risk analysis. Thus, in the present study, hydrological data of the Danube (data on historical maximum levels and flows), topobathymetric data (bathymetric measurements performed on the main Sfantu Gheorghe distributary), roughness coefficient (Manning), and Digital Terrain Model (DTM) were collected. In addition to these data, a lot of other geographical, spatial, regional, etc. data are used.

In this paper, the hydrological data for 2010 were analyzed, respectively the maximum levels and flows (Fig. 3). Analyzing the series of historical data from 2010, in July the maximum level of the Danube was registered at the Tulcea hydrometric station (downstream of the study area). The level reached the value of 4.95 meters with the Sulina Black Sea landmark and had a flow of approximately $16600 \mathrm{~m}^{3} / \mathrm{s}$. Based on the flow hydrograph from 2010, the hydraulic model was calibrated for hydraulic modeling (dynamic method), and based on the maximum level, the GIS analysis of the analyzed locality was performed (static method).

The significant value of the historical flow in July 2010 is due to a strong flood on the Danube that caused floods both in the Danube Delta and upstream. Floods are natural phenomena that are part of the chain of normal events of runoff representing the peak moments in the evolution of the water flow of a river. They are characterized by very rapid increases (of the order of hours), sometimes extraordinary, of the water level and implicit the flow until when a maximum is reached, followed by the also rapid decrease, this can be seen in the chart (Fig. 3), of the waters (but at a slightly slower pace than the increase) which in the end returns to normal flow parameters. 


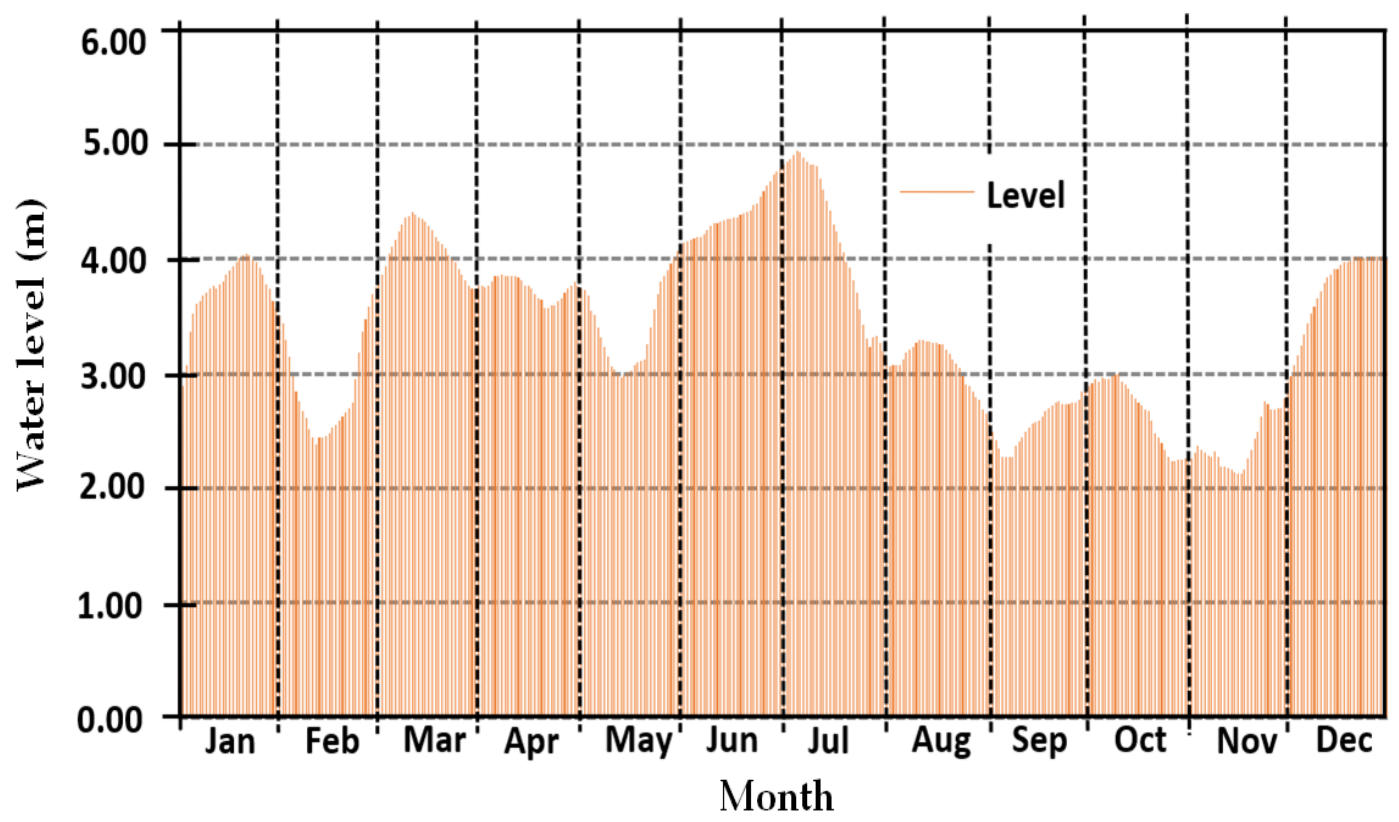

Fig. 3. Monthly evolution of the water levels at the Tulcea hydrometric station during year 2010

The general causes of these flood events are: (a) changes in the general circulation of the atmosphere; (b) lack of torrent correction and soil erosion control works; (c) excessive deforestation in water catchment basins; (d) reducing the carrying capacity of riverbeds by clogging; (e) blocking access bridges and crossings with roots and wood debris brought by torrents; (f) the existence of household fences and household annex buildings bordering the banks of torrents; ( $\mathrm{g}$ ) the location of housing and socio-cultural objectives in floodplains; (h) storage of wood, waste of any kind from citizens' households on the watercourses' banks [11,12].

Both for hydraulic modeling and for GIS analysis, the digital terrain model developed in 2010 by the National Institute for Research - Development of the Danube Delta within the CARTODD project was used. The model obtained is high resolution (1 meter x 1 meter) and represents the information base used both in the approach of the dynamic method and in the approach of the static method. The digital terrain model for the Danube Delta Biosphere Reserve (Fig. 4a) consists of both the digital model of the major riverbed and the digital model of the minor riverbed. The digital model of the minor riverbed was updated by performing topobathymetric measurements on the Sfantu Gheorghe distributary, thus generating transverse profiles distributed at average distances from 100 to 100 meters. The minimum distances between the transverse profiles were calculated at 50 meters in elbows and narrow areas. Between 300 and 500 points with computer content (data on their depth and $\mathrm{x}$ and $\mathrm{y}$ coordinates) were measured on cross-sectional profiles, thus resulting in a very precise digital model of the minor riverbed. The value of the roughness coefficient for the dynamic method is used depending on the character of the minor riverbed, but also on the character of the soil in the area adjacent to the minor riverbed. The value for the roughness coefficient for the Sfantu Gheorghe distributary was set in the range from 0.025 to $0.03[13,14]$.

For the dynamic method, the collected data are processed and entered into the HEC-RAS modeling program. The next step is to process the geometry, namely defining the $2 \mathrm{D}$ flow zoneid consisting of a polygon that covers the study area and the area adjacent to it. The definition of this area is based on the definition of a breach with a width of 30 meters in the protection dam of the Baltenii de Sus locality (Fig. 4b). 
After processing the geometry, the flow hydrograph is defined based on the data series corresponding to July 2010 in the Unstady flow module. The hydraulic modeling process ends after the software runs the input data and the results are obtained. The results obtained are obtained as flood maps for the locality of Baltenii de Sus using several flood levels, presented in Table 1.

Table 1. The flood levels in meters with reference to the Black Sea 75 (BS75) and the Black Sea Sulina (BSS) applied to the settlement

\begin{tabular}{cccccc}
\hline Locality & Reference system & Level 1 & Level 2 & Level 3 & Level 4 \\
\hline \multirow{2}{*}{ Baltenii de Sus } & (m) BS75 & 2.50 & 3.00 & 3.50 & 4.00 \\
\cline { 2 - 6 } & $(\mathrm{m}) \mathrm{BSS}$ & 2.72 & 3.22 & 3.72 & 4.22 \\
\hline
\end{tabular}

The results of the dynamic method correspond to the scenario in which the breach remains open in the protection dam for a period that does not exceed 24 hours. The Global Mapper specialized software was used for GIS analysis in the static method. Data processing in this software was much faster compared to HEC-RAS.
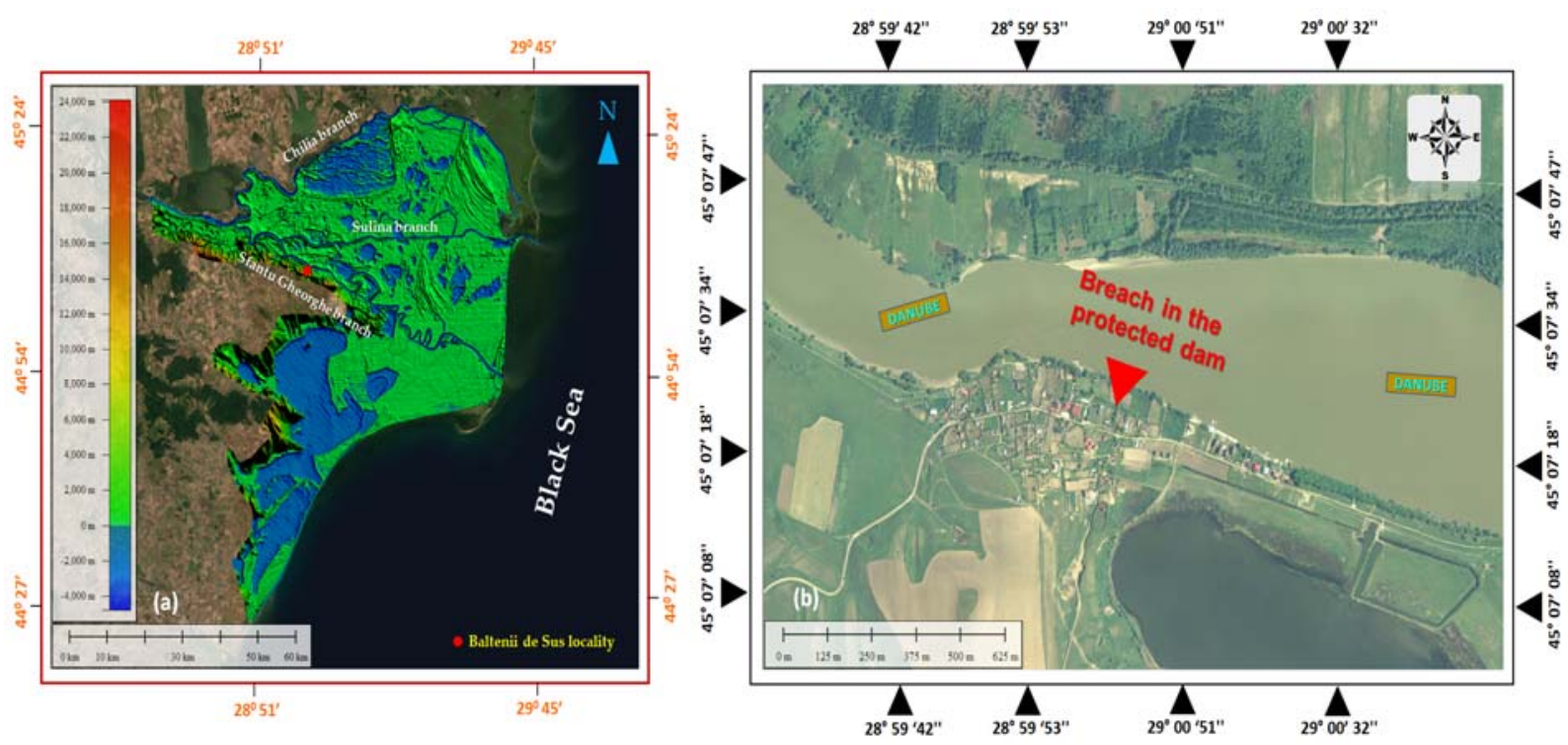

Fig. 4. The location of the settlement overlap the Digital Terrain Model. (a) The Digital Terrain Model for the Danube Delta Biosphere Reserve; (b) The location of the breach in the protection dam of the analyzed settlement

The first step in the Global Mapper software is to establish the projection (STEREO 70 with Datum Dealul Piscului 19710) and bring in the reference system (Black Sea 75) the digital model of the terrain. The study area is cut from DTM (Baltenii de Sus locality and an adjacent area) using the cutting area function. The next step is to raise the water level above the cut area of the DTM using the flood levels in Table 1. This is done using the Water Rise Calculation module. The results of the static method are generated as flood maps for the analyzed locality and correspond to the scenario in which the breach in the protection dam remains open for a long period of time.

\section{RESULTS AND DISCUSSION}

The results obtained are flooding maps at different flood levels for the Baltenii de Sus locality. By the approach of the 2 methods, 8 flood scenarios resulted (4 scenarios for each method) (Fig. 5) and (Fig. 6). The obtained maps show a potentially floodable area in case of major flooding due to the rupture of the protection dam for a period of 24 hours (dynamic method) and over a longer period (static method). 


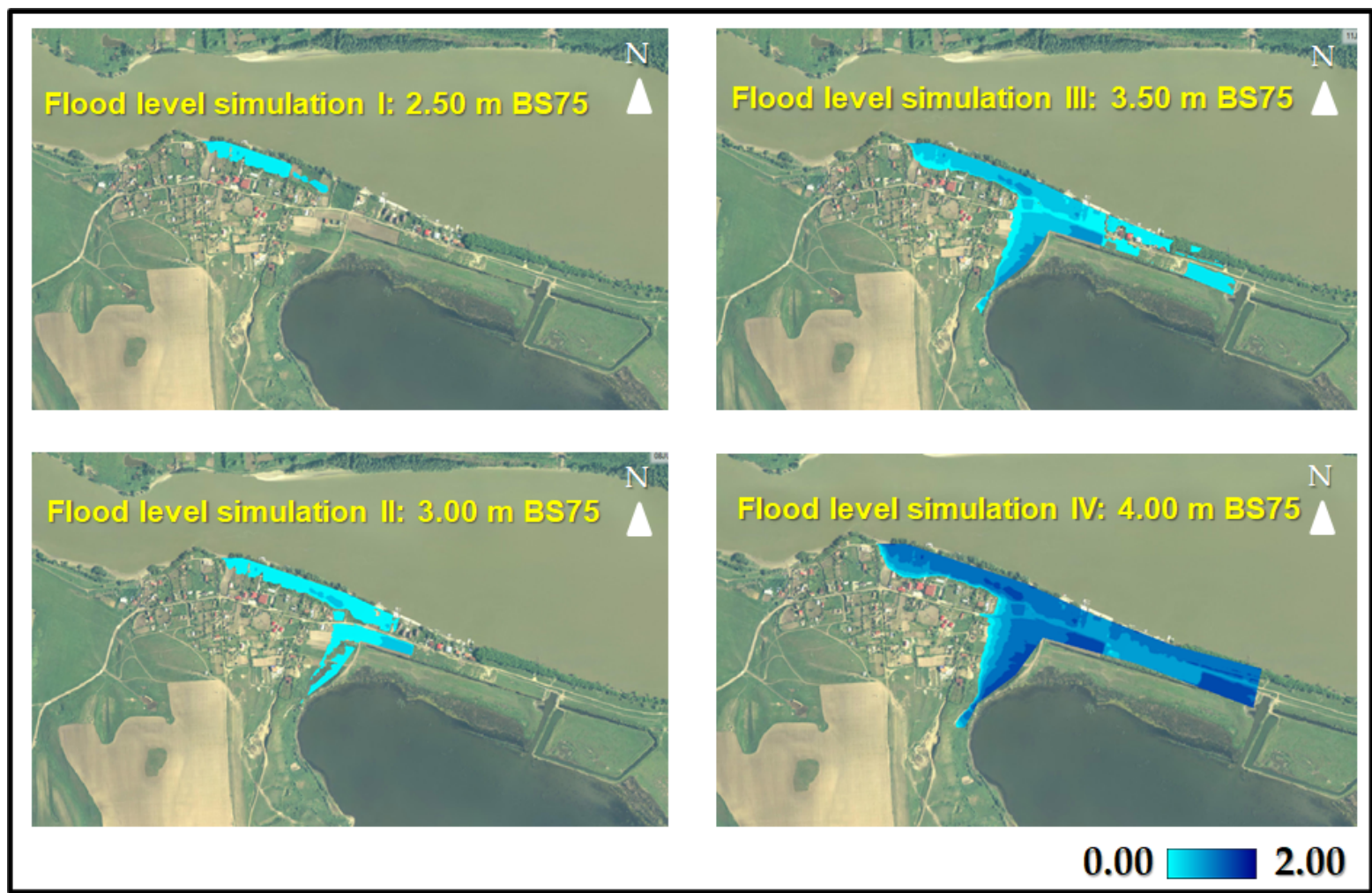

Fig. 5. Flood scenarios maps for Baltenii de Sus settlement using 1D/2D HEC-RAS - Dynamic method

Following the application of the methodology presented in chapter 2, the application of the two methods resulted in flood scenarios for the locality of Baltenii de Sus which can be differentiated depending on the flooded area. The data necessary for the entire analysis process were transformed where it was necessary in the Black Sea reference system 75 . Thus, the results obtained are also displayed in the same reference system for both methods. The maps obtained by the dynamic method show the depth of the flooded surface from 0 to 2 meters for each scenario. The maps obtained by the static method have the depth equal to the difference between the level of flood applied and the elevation of the land in the DTM.

The differences between the two methods are summarized in Table 2. We can say that by applying the static method (GIS analysis with the Global Mapper specialty program), the flooded areas in the analyzed locality are higher in percentage compared to the dynamic method (hydraulic modeling with the HEC-RAS specialty software). The largest differences in flooded area are visible at flood level II and IV, the percentage value being higher than 10 percent.

The negative effects of floods in the study area are significant in case of failure of the protection dam at a maximum level of the Danube and can cause significant damage to the locality analyzed. Flood stage 4 for both methods is the most unfavorable situation in which the flooded area covers more than $50 \%$ of the locality area. 


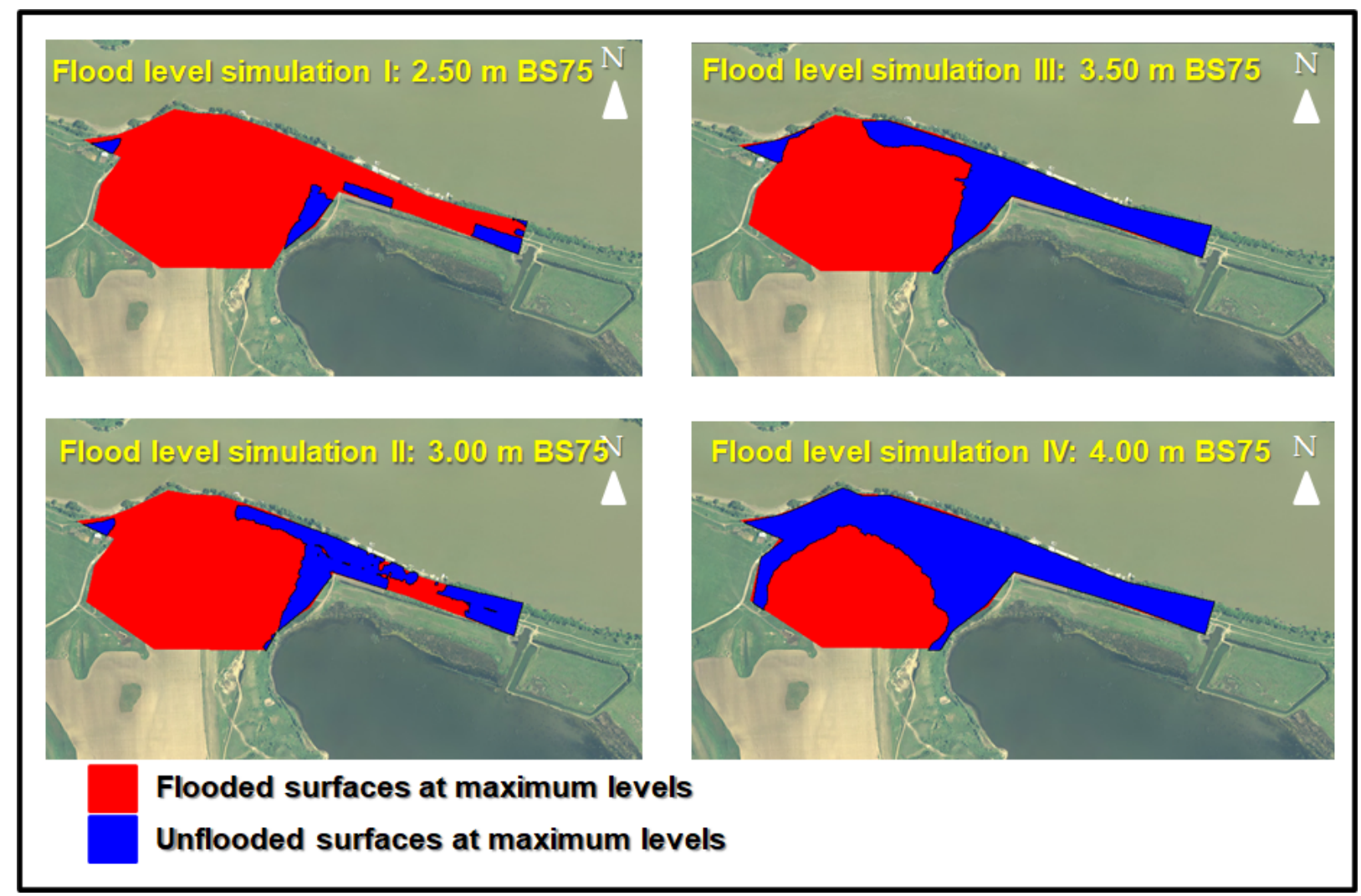

Fig. 6. Flood scenarios maps for Baltenii de Sus settlement using Global Mapper-Static method

Table 2. The synthesis of the results for Baltenii de Sus settlement applying two different methods

\section{Baltenii de Sus settlement}

\begin{tabular}{ccccc}
\hline Stage & Flood level [m] & $\begin{array}{c}\text { Dynamic method - } \\
\text { Floodable surfaces (\%) }\end{array}$ & $\begin{array}{c}\text { Static method - } \\
\text { Floodable surfaces (\%) }\end{array}$ & Difference \% \\
\hline I & H_BS75 $=2.50$ & $4.85 \%$ & $10.12 \%$ & $-5.27 \%$ \\
\hline II & H_BS75 $=3.00$ & $21.16 \%$ & $33.95 \%$ & $-12.79 \%$ \\
\hline III & H_BS75 $=3.50$ & $35.71 \%$ & $44.50 \%$ & $-8.79 \%$ \\
\hline IV & H_BS75 $=4.00$ & $51.34 \%$ & $62.55 \%$ & $-11.21 \%$ \\
\hline
\end{tabular}

\section{CONCLUSIONS}

Flash floods are phenomena that cause significant floods in the Danube Delta. They are characterized by rapid increases (of the order of hours), of the water level, and implicit flow until reaching a maximum, followed by a decrease in water.

In this paper, the flood scenarios for a locality prone to flood risk distributed on the Sfantu Gheorghe distributary were analyzed. The analysis was based on a well-defined methodology that addressed 2 methods. The results obtained are important for many domains such as the construction domain, shipbuilding domain, and are important tools for decision-makers.

The flood maps obtained indicate the potential negative effects associated with floods cases due to the failure of the protective dam over a period of 24 hours (dynamic method) and over a much longer period (static method). 
The large number of households covered by the flood at flood level 4 shows that the population uses land at risk of flooding to live. The analysis of the flood maps shows the extremely important role of the hydrotechnical arrangements around the analyzed locality.

The intensification of torrential rainfall events in Romania in recent years frequently cause floods on the main distributaries of the Danube and can cause major damage in case the protection dams of localities distributed along them fail. Exposed (vulnerable) elements such as households, agricultural areas, and infrastructure in the way of high levels are important and yet very difficult to measure.

The vulnerability of the exposed elements to floods depends on the type of land use and the policy applied in the domain. Vulnerability to floods is also of interest to those responsible for civil protection and emergency intervention, for the regulation of the construction regime in flooded areas. Awareness of vulnerability to floods is of particular interest to those responsible for protecting the population and goods against floods in order to guide future action.

As the climate impact on society has increased, climate variability has become a major concern for flood management decision-makers.

\section{ACKNOWLEDGMENT}

This study was supported by the project "Excellence, performance and competitiveness in the Research, Development, and Innovation activities at "Dunarea de Jos" University of Galati", acronym "EXPERT", financed by the Romanian Ministry of Research and Innovation in the framework of Programme 1-Development of the national research and development system, Sub-programme 1.2Institutional Performance - Projects for financing excellence in Research, Development, and Innovation, Contract no. 14PFE/17.10.2018.

\section{References}

1. Sageata R., Dumitrescu B., Grigorescu I., Persu M, Typologies regarding the flood vulnerability of Romanian cities, J. Wulfenia, 11 (2013) 274-290.

2. Popa P., Timofti M., Voiculescu M., Dragan S., Trif C., Georgescu L.P., Study of PhysicoChemical Characteristics of Wastewater in an Urban Agglomeration in Romania, SCIENTIFIC WORLD JOURNAL, pp. 1-10, 2012.

3. Rusu L., Butunoiu D., Rusu E., Analysis of the extreme storm events in the Black Sea considering the results of a ten-year wave hindcast, Journal of environmental protection and ecology 15 (2) (2014) 445-454.

4. Negru O., Patrut S., Tone A., Management of emergency situations generated by floods in Romania, Ministry of Environment and Forests, Romania, pp. 131-136, 2010.

5. Romanescu G., Stoleriu C. Anthropogenic interventions and hydrological-risk phenomena in the fluvial-maritime Delta of the Danube (Romania), Ocean \& Coast. Management 102 (2014) 123-130.

6. Armas I., Ionescu R., Posner C., Flood risk perception along the Lower Danube river Romania, Nat. Hazards 79 (2015) 1913-1931.

7. Banescu A., Georgescu L.P., Rusu E, Murariu G., Analysis of the floods risk in a sector from the Danube Delta using GIS technologies, 18 International Multidisciplinary Scientific GeoConference SGEM, Bulgaria, pp. 1-9, 2018.

8. Iticescu L.P., Georgescu L.P., Topa C.M., Murariu G., Monitoring Danube water quality near Galati City, Journal of Environmental Protection and Ecology 15 (2014) 30-38.

9. Banescu A., Georgescu L.P., Iticescu C., Rusu E., Analysis of river level and the volume flow on the Danube close to the city of Tulcea, based on in situ measurements, Journal of Marine technology and Environment 1 (2018) 7-13.

10. Iticescu C., Georgescu L.P., Gurau G., Murarescu M., Dima D., Murariu G., Gheorghies C., Methods to reduce environmental impact of municipal waste water sewage sludge, Environmental Engineering and Management Journal 14 (2015) 2457-2463. 
11. Dragomir C.M., Constantin D,E., Voiculescu M., Georgescu L.P., Merlaud A., Roozendael M.V., Modeling results of atmospheric dispersion of NO2 in an urban area using METI-LIS and comparison with coincident mobile DOAS measurements, Atmospheric Pollution Research 6 (2015) 503-510.

12. Constantin D.E., Voiculescu M., Georgescu L.P., Satellite Observations Of No2 Trend Over Romania, The Scientific World Journal 1 (2013) 1-10.

13. Meier A.C., Schönhardt A., Bösch T., Richter A., Seyler A., Ruhtz T., Constantin D.E., Shaiganfar R., Wagner T., Merlaud A., Roozendael V., Belegante M., Nicolae D., Georgescu L.P., Burrows J.P., High-resolution airborne imaging DOAS measurements of NO2 above Bucharest during AROMAT, Atmos. Meas. Tech 10 (2017) 1831-1857.

14. Rusu E., Măcuta S., Numerical modelling of longshore currents in marine environment, Environmental Engineering \& Management Journal 8 (1) (2009) 147-151. 